UCRL-ID-124080

\title{
Summary of the Engineering Analysis Report for the Long-Term Management of Depleted Uranium Hexafluoride
}

\author{
J. W. Dubrin \\ L. Rahm-Crites
}

Prepared for the Department of Energy by

Lawrence Livermore National Laboratory

September 1997

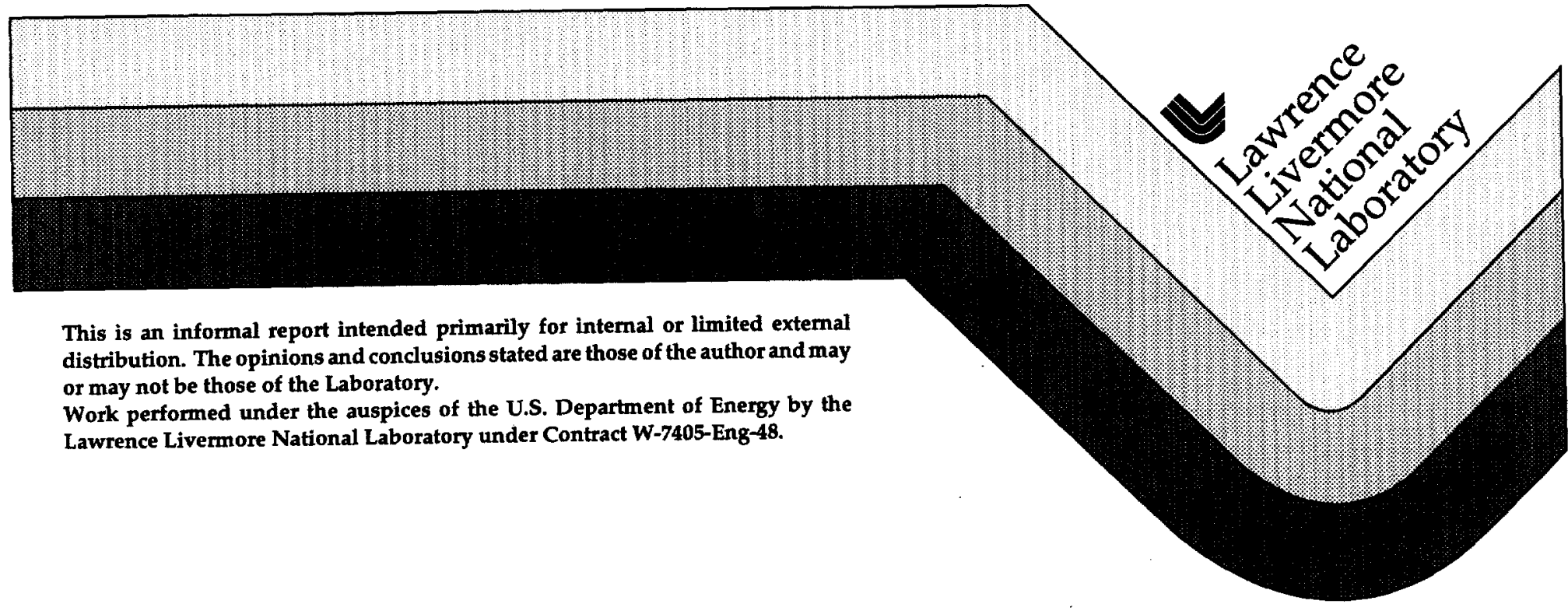




\section{DISCLAIMER}

This document was prepared as an account of work sponsored by an agency of the United States Government. Neither the United States Government nor the University of California nor any of their employees, makes any warranty, express or implied, or assumes any legal liability or responsibility for the accuracy, completeness, or usefulness of any information, apparatus, product, or process disclosed, or represents that its use would not infringe privately owned rights. Reference herein to any specific commercial product, process, or service by trade name, trademark, manufacturer, or otherwise, does not necessarily constitute or imply its endorsement, recommendation, or favoring by the United States Government or the University of California. The views and opinions of authors expressed herein do not necessarily state or reflect those of the United States Government or the University of California, and shall not be used for advertising or product endorsement purposes.

This report has been reproduced directly from the best available copy.

Available to DOE and DOE contractors from the Office of Scientific and Technical Information

P.O. Box 62, Oak Ridge, TN 37831

Prices available from (615) 576-8401, FTS 626-8401

Available to the public from the

National Technical Information Service

U.S. Department of Commerce

5285 Port Royal Rd.,

Springfield, VA 22161 


\section{Summary of the \\ ENGINEERING ANALYSIS REPORT \\ for the Long-Term Management of Depleted Uranium Hexafluoride}

Note: This summary condenses and simplifies a mumber of technical issues and ideas. To obtain a fuller understanding of particular issues and ideas, the reader is urged to consult the complete Engineering Analysis Report.

\section{Introduction}

The Department of Energy is reviewing ideas for the long-term management and use of its depleted uranium hexafluoride.

The Department of Energy (DOE) owns about 560,000 metric tons (over a billion pounds) of depleted uranium hexafluoride $\left(\mathrm{UF}_{6}\right)$. This material is contained in steel cylinders located in storage yards near Paducah, Kentucky, and Portsmouth, Ohio, and at the East Tennessee Technology Park (formerly the K-25 Site) in Oak Ridge, Tennessee.

Uranium herafluoride (UF) is a compound of one part uranium to six parts fluorine. At room temperature, it is a white solid similar to rock salt. It is usually measured in metric tons (MT). One MT equals about 2200 pounds.

On November 10, 1994, DOE announced its new Depleted Uranium Hexafluoride Management Program by issuing a Request for Recommendations and an Advance Notice of Intent in the Federal Register (59 FR 56324 and 56325). The first part of this Program consists of engineering, cost, and environmental impact studies. Part one will conclude with the selection of a long-term management plan, or strategy. Part two will carry out the selected strategy.

\subsection{Background-What Is Depleted Uranium Hexafluoride?}

Uranium is made up of several different types of atoms. One of these, uranium-235 (U-235), can be made to split apart and release a large amount of energy. As found in nature, uranium contains only a very small amount of U-235. In order for uranium to produce significant amounts of energy, the percentage of U-235 must be increased. For example, uranium fuel for powerplants usually contains between three and five percent $U-235$, while natural uranium contains only about 0.71 percent U-235. Uranium with more than 0.71 percent $U-235$ is called "enriched" uranium.

The enrichment process used in the United States is gaseous diffusion. It was first used on a large scale in the 1940s as part of the Manhattan Project in Oak Ridge, Tennessee. Later, plants were also built at Paducah, Kentucky, and Portsmouth, Ohio. On July 1, 1993, DOE leased these two plants to the United States Enrichment Corporation, as required by the Energy Policy Act of 1992. Oak Ridge had stopped enriching uranium in 1985. 
The first step in gaseous diffusion is to heat solid natural $\mathrm{UF}_{6}$ until it becomes a gas. The $\mathrm{UF}_{6}$ gas is repeatedly separated into two streams. Gradually, one stream gains U-235, while the other loses U-235. When the U-235 in this second stream has been reduced to between 0.2 and 0.4 percent, the depleted $U_{F}$ is removed from processing and placed in storage. Between 1945 and July 1, 1993, about 560,000 MT of depleted $\mathrm{UF}_{6}$ was stored at the three gaseous diffusion plant sites.

Why is there so much depleted $\mathrm{UF}_{6}$ ? For every pound of enriched uranium, between eight and nine pounds of depleted uranium are produced.

DOE's depleted $\mathrm{UF}_{6}$ is stored in a partial vacurum inside steel cylinders. Most cylinders are about twelve feet long and 48 inches in diameter and hold between 9 and $12 \mathrm{MT}$ of solid depleted $\mathrm{UF}_{6}$. In all, there are 46,422 cylinders:

$$
\begin{aligned}
& 28,351 \text { at Paducah } \\
& 13,388 \text { at Portsmouth } \\
& 4,683 \text { at Oak Ridge. }
\end{aligned}
$$

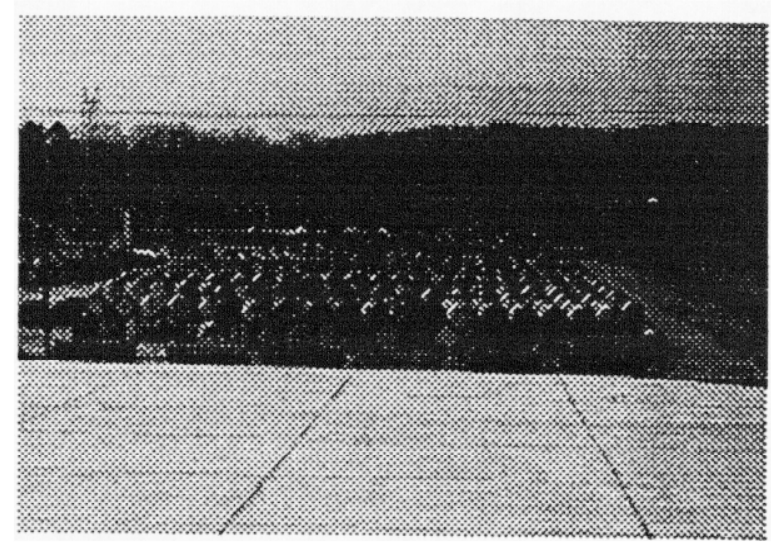

\subsection{Selecting a Management Strategy}

The current management strategy is to continue safe storage of the depleted $\mathrm{UF}_{6}$ cylinders in the existing storage yards. Activities in this strategy include inspection, handling, monitoring, and maintenance, as needed, to keep the cylinders in good condition. Other possible management strategies could involve use of the depleted uranium, long-term storage, disposal, or some combination of these. A complete management strategy may include a number of different activities. Examples are transportation or conversion of the depleted $\mathrm{UF}_{6}$ to another chemical form, such as an oxide or metal.

The Draft Programmatic Environmental Impact Statement (Draft PEIS) looks at six alternative strategies for the long-term management of depleted $\mathrm{UF}_{6}$. They include the current management strategy (the "No Action alternative"), two alternatives for long-term storage, two alternatives for use, and one for disposal. DOE's preferred alternative is to use 100 percent of the depleted uranium, either as uranium oxide or uranium metal, or a combination of both. The fluorine in the depleted $\mathrm{UF}_{6}$ would also be used.

The Engineering Analysis Report contains the technical data on which the Draft PEIS and the cost analysis are based. The PEIS, the Cost Analysis Report, and the Engineering Analysis Report will help DOE select a management strategy. The Record of Decision is expected in 1998. 


\section{The Engineering Analysis Project}

Data from the engineering analysis will help DOE compare the environmental impacts and costs of management strategy alternatives.

In November 1994, DOE asked members of the public, industry, and other government agencies to submit recommendations for the use or long-term management of depleted UF 6 . Fifty-seven replies were received and reviewed by independent technical experts. The results were published in the Technology Assessment Report in June 1995. Most of the recommendations were judged to be feasible, or capable of being carried out now or in the near future. These ideas and technologies were analyzed in more detail.

The main part of the Engineering Analysis Project developed engineering data for the feasible technology options. The data inchude general layouts for facilities, descriptions of processes, and analysis of hazards.

\subsection{Work Breakdown Structure}

A work breakdown structure shows the work that will need to be done on a project, moving from a general level to more and more detailed levels. It provides an orderly way to analyze and compare complex management strategies. Figure 1 shows the first three levels of the work breakdown structure for depleted $\mathrm{UF}_{6}$ management.

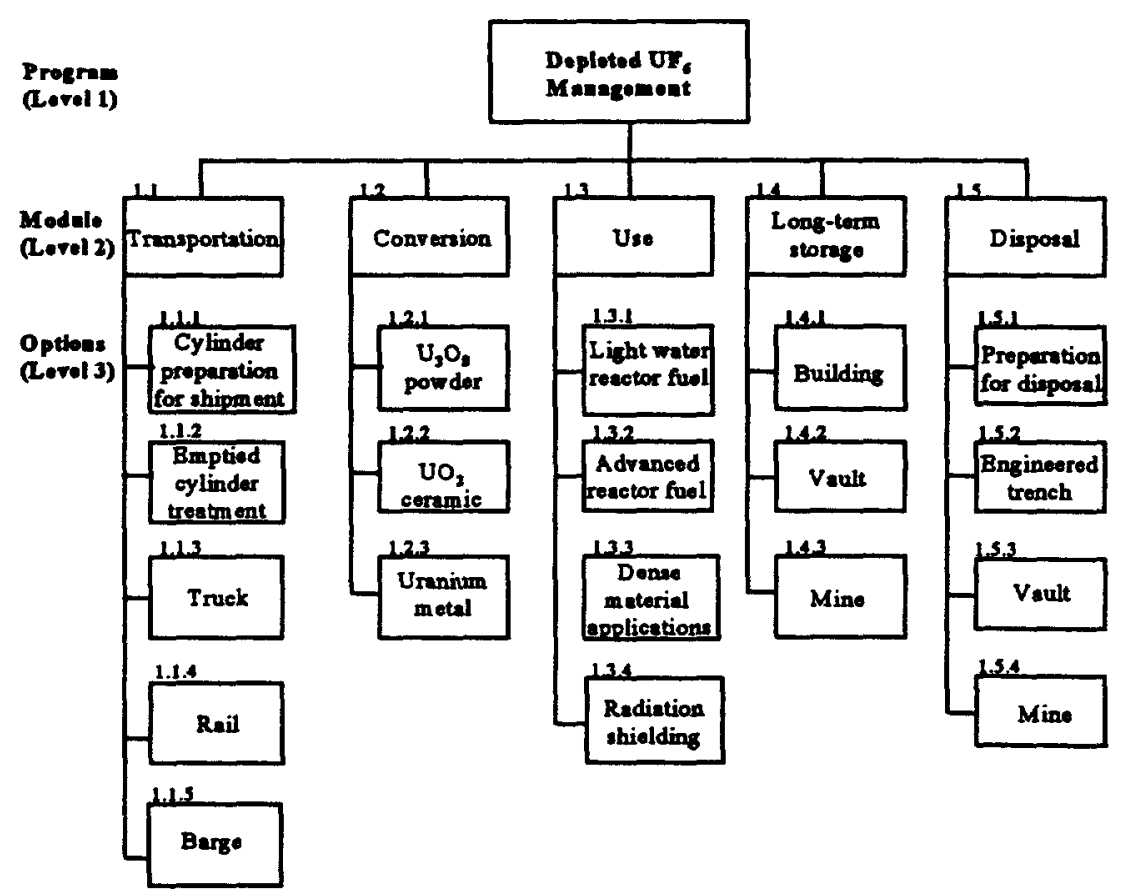

Figure 1. Depleted UF, Management Work Breakdown Structure, Showing Modules (Level 2) and Options (Level 3) 
The recommendations received early in the Engineering Analysis Project fell into several general categories. These general categories are called modules because they are the most basic building blocks for management strategies (see Level 2 in Figure 1). The modules are transportation, conversion, use, long-term storage, and disposal. Most management strategy alternatives combine two or more of these five modules. For example, conversion of the depleted $\mathrm{UF}_{6}$ to another chemical form in involved in the use and disposal alternatives and in one of the long-term storage alternatives. Transportation of materials occurs in all strategies except the No Action alternative.

In each module, there are various options (Level 3 in Figure 1), or different ways of doing things. For example, in the long-term storage moctule there are three different options for the type of facility in which the depleted uranium could be stored: building, vault, and mine.

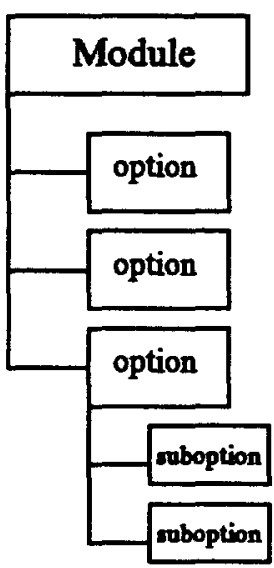

Figure 2. Modules are broken down into options. Options are broken down into suboptions.
The next level of detail after options is called suboptions. For example, the long-term storage facility types are further broken down by the forms of depleted uranium which might be stored in each. Figure 2 shows the general relationship among modules, options, and suboptions.

The Engineering Analysis Report focuses on technology options and suboptions. Data for the options and suboptions can be combined to provide overall data for alternatives. To get a better idea of how options and suboptions were linked together to form management strategy alternatives, see Figure 3, which appears at the end of this Summary.

\subsection{Methodology}

The Engineering Analysis Report contains 13 Engineering Data Input Reports, covering the specific options and suboptions named in the unshaded boxes in Table 1. These are the options and suboptions which were analyzed in depth. Options and suboptions which were analyzed in less detail are discussed in Chapter 4 of the Engineering Analysis Report.

Each Data Input Report inchudes layouts for facilities, descriptions of processes, estimates of wastes and emissions, estimates of resources and workers needed, hazard assessments, accident scenarios, and transportation information. The data are estimates based on an early stage of design. More detailed data for specific technologies will be developed in the second part of the Program. 
Table 1. Options and Suboptions for the Various Modules

(Note: shaded boxes are principal options and suboptions analyzed in less detail)

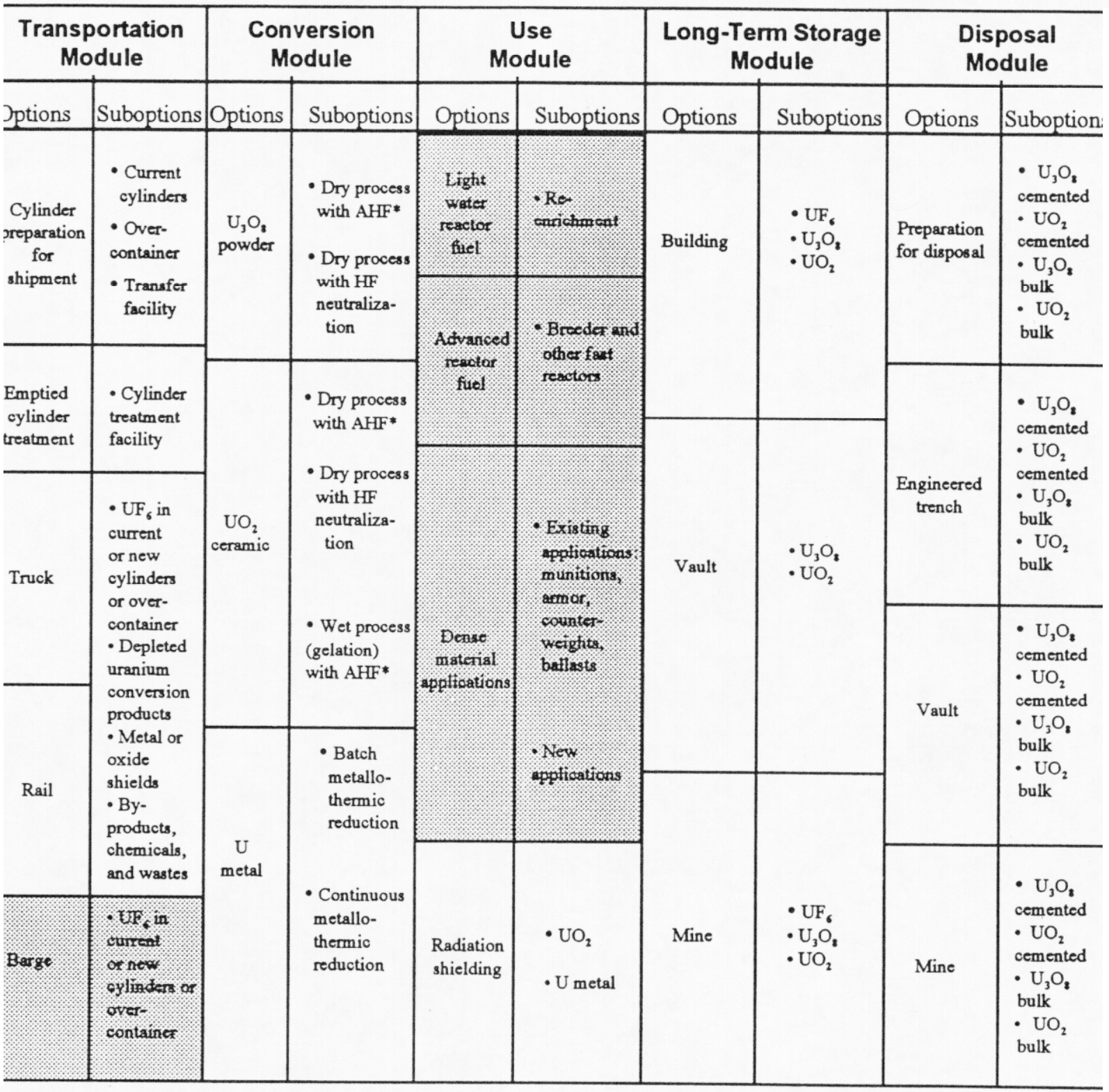

- Anhydrous hydrogen fluoride (HF) 
Examples of assumptions used in the engineering analysis:

- Total time for project: 20 years.

- Processing rate: 28,000 MT (60 million pounds) of depleted $\mathrm{UF}_{6}$ per year. density and the same type of packaging for transportation.

- Facilities are newly built on previously unused sites.
- Each of the different forms of depleted uranium would always have the same bulk

To make it easier to compare the different options and suboptions, data were based on certain common assumptions.

Estimates based on different processing rates ( 50 percent and 25 percent of the assumed rate) were made for several technologies and are included in Chapter 8 of the Engineering Analysis Report.

Each Engineering Data Input Report includes its own analysis of reasonably foreseeable accidents involving radiological or hazardous materials. There is also an accident analysis in Chapter 7 which discusses two particular types of accidents: (1) accidents associated with depleted $\mathrm{UF}_{6}$ cylinder handling and storage and (2) accidents which would have significant hazardous and/or radiological material releases but have a very low probability. In general, the higher the consequences of an accident, the less frequently such an accident is likely to occur. The accidents discussed in Chapter 7 are what are called "incredible" accidents, which means that their likelihood of occurrence is between once in one million years and once in ten million years.

The Engineering Analysis Report also includes discussions of license, permit, and regulatory requirements and changes in regulations for the transportation of depleted $\mathrm{UF}_{6}$ cylinders.

\section{Summary of Options Analyzed in Depth}

Feasible technologies for which data could be developed were analyzed in depth.

Options which were judged to be feasible in the Technology Assessment Report were analyzed in depth. These are general types of technologies, but they have enough technical basis to allow engineers to develop the data needed for estimates of environmental impacts and costs. Additional options, most of which are at an earlier stage of development, were also considered. These are described in the Engineering Analysis Report but are analyzed in less detail.

This section describes the technology options and suboptions which were analyzed in depth. They are grouped into the five modules in the work breakdown structure. The modules are printed in boldface type and the options are underlined. Table 1 gives an overall summary of the information.

\subsection{Transportation Module}

All of the Engineering Data Input Reports include a discussion of transportation of materials by both truck and rail. Materials which would be transported would include depleted $\mathrm{UF}_{6}$, depleted uranium in 
other chemical forms (after conversion), manufactured products for use, and other materials such as byproducts and wastes.

Two transportation options, preparation of depleted $U_{6}$ cylinders for shipment and treatment of emptied cylinders, are analyzed in depth.

Cylinder Preparation for Shipment. All alternatives in the Draft PEIS, except for the No Action alternative, assume that depleted $\mathrm{UF}_{6}$ cylinders will be moved from their current locations. Transportation of cylinders is regulated by the Department of Transportation (DOT). These regulations involve (1) the amount of depleted $\mathrm{UF}_{6}$ inside the cylinder, (2) the pressure inside the cylinder, and (3) the condition of the cylinder, especially the thickness of the steel walls. Some cylinders meet the DOT requirements and would require minimal preparation, but some have technical problems and would require additional work.

There are two suboptions for preparing cylinders with technical problems for shipment. In the overcontainer suboption, the cylinder would be placed inside a container which meets DOT regulations. In the transfer facility suboption, the depleted $\mathrm{UF}_{6}$ would be transferred to a new cylinder. Using the overcontainer would require less handling and produce less waste. It would also avoid the construction of a special facility. A transfer facility would be expected to have greater impacts, but it could be used in developing an alternative for long-term storage of depleted $\mathrm{UF}_{6}$ in new cylinders.

Emptied Cylinder Treatment. In most of the management strategies, the depleted UF 6 would be taken out of the cylinders and converted to another chemical form. Any depleted UF 6 left in the emptied cylinder (called the "heel") would be washed out with water. After the water evaporates, the mixture of depleted uranium and fluorine would be converted to solid uranium oxide and hydrogen fluoride (HF) gas. Hydrogen fhuoride gas is corrosive. To neutralize it, or make it harmless, lime would be added, forming

calcium fluoride $\left(\mathrm{CaF}_{2}\right)$. The analysis assumes that the cleaned, emptied cylinders will be stored as scrap metal at the gaseous diffusion plant sites.

\subsection{Conversion Module}

Most management strategy alternatives require converting the depleted $\mathrm{UF}_{6}$ to another chemical form. Three other chemical forms of depleted uranium are analyzed in depth: triuranium octaoxide $\left(\mathrm{U}_{3} \mathrm{O}_{8}\right)$ powder, uranium dioxide $\left(\mathrm{UO}_{2}\right)$ ceramic, and uranium metal. The oxides are compounds of uranium and oxygen. Because the oxides are very stable and slow to dissolve in water, they are presently the preferred forms for long-term storage and disposal. Very dense depleted $\mathrm{UO}_{2}$ and depleted uranium metal are preferred for use in shielding for spent nuclear fuel because they are good at absorbing the kind of radiation called gamma rays. Depleted uranium metal is preferred for most dense material applications, which need high density and mass.

Conversion starts by heating solid depleted $\mathrm{UF}_{6}$ to produce a gas. All the conversion processes being analyzed in depth produce large quantities of hydrogen fluoride (HF). Uranium hexafluoride and HF are the most significant chemical hazards to the environment and workers during conversion. The designs 
1. $U_{3} Q_{8}$ (three parts uranium to eight parts oxygen) powder

2. $\mathrm{UQ}_{2}$ (ane part uranim to two parts axygen) pellets tiny dense spheres

3. Uranim matal

for the conversion process buildings and the HF storage buildings use reinforced concrete for added safety. Temperatures in the HF storage buildings would be kept between $45^{\circ}$ and $55^{\circ}$ Fahrenheit. This would prevent the HF from becoming a gas that a worker might inhale in case of a spill.

The conversion facilities would be expected to operate about 7000 hours per year. They would have enough outdoor storage for one month's supply of full depleted $\mathrm{UF}_{6}$ cylinders. There would also be enough indoor storage space for three months' supply of nearly empty cylinders. This would allow time for short-lived radioactive products in the heel to decay $\mathrm{UF}_{6}$ Conversion Products
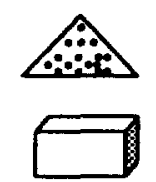

the facilities would include storage for one month's

$\mathrm{U}_{3} \mathrm{O}_{8}$ Option. Two suboptions are analyzed for converting depleted $\mathrm{UF}_{6}$ to depleted $\mathrm{U}_{3} \mathrm{O}_{8}$. (The conversion of $\mathrm{UF}_{6}$ to an oxide is referred to as "defluorination" because fluorine atoms are removed.) Both suboptions use a two-step process in which depleted $\mathrm{UF}_{6}$ reacts with steam at high temperatures. This is called a "dry" process, as opposed to "wet" processes, in which the main reactions occur in water. The process produces depleted $\mathrm{U}_{3} \mathrm{O}_{8}$ in fluffy powder form and concentrated $\mathrm{HF}$, which is about 70 percent $\mathrm{HF}$ and about 30 percent water. After the depleted $\mathrm{U}_{3} \mathrm{O}_{8}$ is compacted, it would have a bulk or packing density of about 3 grams per cubic centimeter (about $13 / 4$ ounces per cubic inch).

The first $\mathrm{U}_{3} \mathrm{O}_{8}$ suboption uses distillation to reduce the water content in the concentrated $\mathrm{HF}$ to one percent or less. The resulting HF vapor is called anhydrous HF (AHF), meaning that it has very little water. It is expected that the uranium content will be low enough that the AHF can be sold for use. The second $\mathrm{U}_{3} \mathrm{O}_{8}$ suboption would neutralize the $\mathrm{HF}$ to produce $\mathrm{CaF}_{2}$ for sale or disposal.

$\mathrm{UO}_{2}$ Option. Uranium dioxide in the ceramic form is very dense. Depending on the shape and size of its particles, the $\mathrm{UO}_{2}$ will generally be two to three times denser than compacted $\mathrm{U}_{3} \mathrm{O}_{8}$ powder. The denser product would require less space for storage or disposal. The denser form could also be used in depleted uranium concrete for radiation shielding.

There are three suboptions for converting depleted $\mathrm{UF}_{6}$ to depleted $\mathrm{UO}_{2}$. Two of them use a dry process (similar to the one described above for $\mathrm{U}_{3} \mathrm{O}_{8}$ ) to make $\mathrm{UO}_{2}$ powder. The $\mathrm{UO}_{2}$ powder is pressed into pellets about 2 centimeters $(3 / 4$ inch) in diameter. To increase their density, the pellets are then heated at about $1700^{\circ}$ centigrade (about $3092^{\circ}$ Fahrenheit). The furnaces are expected to be larger than those currently used in nuclear fuel manufacturing plants. One of the dry process suboptions provides an AHF by-product and the other neutralizes the HF. 
The third technology suboption is based on a "wet" process which produces dense depleted $\mathrm{UO}_{2}$ in the form of very small spheres of a millimeter (about $1 / 20$ inches) or less in diameter. These tiny particles can be packed very close. The process, called "gelation," dissolves $\mathrm{U}_{3} \mathrm{O}_{8}$ in an acid. Various chemicals are added and the solution is fed through nozzles which break it into small droplets. These droplets are then decomposed into jelly-like spheres of depleted uranium oxide. These are further processed and finally heated at high temperatures. Gelation has yet to be proven as an industrial process; therefore, the technological uncertainties with the wet process are greater than with the more developed dry processes.

Uranium Metal Option. The analysis considers two suboptions, a batch process and a continuous process, for converting depleted $\mathrm{UF}_{6}$ to depleted uranium metal. Both processes start by combining depleted $\mathrm{UF}_{6}$ with hydrogen to make depleted uranium tetrafluoride $\left(\mathrm{UF}_{4}\right)$ and AHF. In the second step, magnesium (Mg) is used to remove the fluorine from the $\mathrm{UF}_{4}$ (known as "reduction"). Because it uses a metal, $\mathrm{Mg}$, and takes place at high temperatures, this process is called "metallothermic reduction."

The batch process is the standard industrial process. A mixture of depleted $\mathrm{UF}_{4}$ and $\mathrm{Mg}$ metal is heated in a sealed steel container until it forms liquid depleted uranium metal and a magnesium fluoride $\left(\mathbf{M g F}_{2}\right)$ by-product. The denser uranium metal settles to the bottom and the $\mathrm{MgF}_{2}$ collects on top. After the container has cooled, the solid depleted uranium metal and $\mathrm{MgF}_{2}$ are removed and separated from each other. The by-product contains some uranium. Without further treatment, it would have to be disposed of as a radioactive low-level waste. The design for the batch process includes a step for removing uranium from the $\mathrm{MgF}_{2}$. It is assumed that, after this step, the $\mathrm{MgF}_{2}$ could be disposed of as a nonhazardous solid waste.

The other suboption analyzed in depth is the continuous process, which is currently being developed. In this process, depleted $\mathrm{UF}_{4}$ and $\mathrm{Mg}$ are continuously fed into a heated container. The dense liquid uranium metal settles to the bottom and is removed. The liquid $\mathrm{MgF}_{2}$ forms a middle layer and is separately removed. The liquid $\mathrm{Mg}$ floats on the top.

The continuous process has three possible advantages over the batch process: (1) a higher processing rate, (2) a lower level of uranium in the by-product, and (3) a liquid depleted uranium product which could be directly formed into an end product. The early design assumes that the amount of uranium in the by-product will be small enough that a decontamination step would be unnecessary. Based on the design, the continuous process would have a lower cost than the batch process. However, since the continuous process is still being developed, the technological uncertainties are greater.

\subsection{Use Module}

The use option analyzed in depth is to make depleted uranium into a shielding material to put around spent nuclear fuel. The fuel in nuclear powerplants has to be replaced every so often. The used-up, or spent, nuclear fuel (SNF) is still radioactive and must be shielded. The Engineering Analysis Report analyzes two suboptions for use as radiation shielding, but this is only one of several possible uses for depleted uranium. Other uses include fuel for light (regular) water reactors or advanced reactors and 
dense material applications. Section 4.3 discusses use options which were analyzed in less detail. The two radiation shielding suboptions analyzed in depth are examples of possible uses.

Radiation Shielding Option - $\mathrm{UQ}_{2}$ Suboption. This suboption would use depleted uranium in the form of $\mathrm{UO}_{2}$ pellets. These dense pellets can be used instead of gravel to make concrete shielding for SNF storage containers. Depleted uranium concrete, also known as DUCRETE ${ }^{T M}$, provides shielding with less weight and bulk than regular concrete. It might also be usable in overcontainers for SNF disposal, but this use has yet to be developed.

In the designs for storage containers, the depleted uranium concrete is enclosed inside stainless steel. The shielding manufacturer receives partly finished steel shells and other parts and puts the containers together in one building. In another building, where radiological materials can be handled, depleted $\mathrm{UO}_{2}$ pellets from a conversion plant are combined with sand, cement, and water, and the depleted uranium concrete is poured between the stainless steel shells. After the cement hardens, the container is completed.

Radiation Shielding Option - Uranium Metal Suboption. This suboption would manufacture depleted uranium metal into shields for use inside a multi-purpose unit system. A multi-purpose unit is a container that would provide confinement of SNF during storage, transportation, and disposal.

In this design, the manufacturer receives depleted uranium metal (or alloy), partly completed stainless steel or metal alloy shells, and other pieces to enclose the uranium metal. The containers are put together in one building. In a separate building, where radiological materials can be handled, the depleted uranium metal is melted and poured between the steel or alloy shells. After the depleted uranium metal cools, the container is completed.

\subsection{Long-Term Storage Module}

Long-term storage means that the depleted uranium could be used at some later date. Three long-term storage options are analyzed in depth: (1) storage in a building, (2) storage in a below ground vault, and (3) storage in a mine. The suboptions are the chemical forms in which the depleted uranium is stored. Three forms are considered for storage in buildings or mines: $\mathrm{UF}_{6}, \mathrm{U}_{3} \mathrm{O}_{8}$, and $\mathrm{UO}_{2}$. Two forms are considered for storage in vaults: $\mathrm{U}_{3} \mathrm{O}_{2}$ and $\mathrm{UO}_{2}$. These chemical forms have very different bulk densities. A denser product takes up less space and could therefore cost less to store. This analysis assumes that the tiny, dense $\mathrm{UO}_{2}$ spheres produced by the gelation process would need the least storage space and $\mathrm{U}_{3} \mathrm{O}_{8}$ powder would need the most storage space.

The building option uses metal framed buildings for storage. The below ground vault would be made of reinforced concrete with a steel roof supported by trusses. Storage in a mine would use underground tunnels. 


\subsection{Disposal Module}

The engineering analysis for this module considers three options for disposal: (1) disposal in an engineered trench, (2) disposal in a below ground vault, and (3) disposal in a mine. The engineered trench is an 8-meter (26-foot) deep trench covered with a sloping cap of closely packed clay and other barriers. This option would work best in drier areas.

A form which is stable and slow to dissolve is preferred for disposal. Therefore, the chemical forms analyzed for disposal are the oxides, $\mathrm{U}_{3} \mathrm{O}_{8}$ and $\mathrm{UO}_{2}$. In addition, the depleted uranium oxide powder or pellets may either be mixed with cement before disposal or disposed of in bulk form inside drums. Altogether, there are four waste form suboptions: (1) cemented $\mathrm{U}_{3} \mathrm{O}_{2}$, (2) cemented $\mathrm{UO}_{2},(3)$ bulk $\mathrm{U}_{3} \mathrm{O}_{8}$, and (4) bulk $\mathrm{UO}_{2}$. Each disposal facility option is analyzed for all four waste forms.

The analysis covers a wide range of conditions, including variations in the climate and geology of possible disposal locations and variations in the amount of disposal space needed. Cemented $\mathrm{U}_{3} \mathrm{O}_{8}$ requires the most space because $\mathrm{U}_{3} \mathrm{O}_{8}$ is less dense than $\mathrm{UO}_{2}$ and because the cement adds to the mass. The form requiring the least space for disposal is bulk $\mathrm{UO}_{2}$.

All the disposal facility designs include a waste form facility (preparation for disposal option). This is where the depleted uranium oxide is received from the conversion plant. For cemented waste forms, preparation would include mixing the oxide with cement, repackaging it in new or recycled drums, and allowing it to harden. Bulk waste forms would require less preparation.

\section{Summary of Principal Options and Technologies Analyzed in Less Detail}

Technologies analyzed in less detail in this part of the Program are preserved for the second part of the Program.

Most of the options considered in the engineering analysis were replies to DOE's Request for Recommendations. The technologies discussed in Section 3 are general types, but they have enough technical basis to allow engineers to develop data which can be used to estimate environmental impacts and costs. A number of other technologies were also recommended. These options are promising but are analyzed in less detail for one or more of the following reasons: they are in earlier stages of design or development; they would take more time than the 20-year schedule assumed in this analysis; they are proprietary; they involve uses of depleted uranium which are already in practice.

Technologies analyzed in less detail during the first part of the Depleted Uranium Hexafluoride Program are still kept for the next part of the Program. These technologies are briefly described below. The options and suboptions analyzed in depth are general enough that the estimates made could cover a variety of specific technologies. 


\subsection{Transportation Module}

Transport by barge was considered. However, at this time the locations for most activities are unknown and the possibility of using barge transportation is uncertain. All three gaseous diffusion plant sites mainly use ground transportation. Except for the East Tennessee Technology Park, facilities for using barges would have to be developed.

\subsection{Conversion Module}

Many good ideas for conversion technologies were submitted. In general, they are in the early stages of design or development. Some of them are also proprietary. When more fully developed, these processes might offer such advantages as more flexibility, fewer processing steps, reduced environmental impacts, lower costs, and higher profits.

Uranium Oxide Suboptions. A number of responses recommended using the well-known dry process for converting $\mathrm{UF}_{6}$ to an oxide with an AHF by-product. There were also several recommendations for newer technologies with important features. One example uses a wet process to convert depleted $\mathrm{UF}_{6}$ to an intermediate compound which is then heated and converted to depleted $\mathrm{U}_{3} \mathrm{O}_{8}$. Anhydrous hydrogen fluoride is directly produced. Another technology uses a liquid metal such as iron to speed up the decomposition of depleted $\mathrm{UF}_{6}$. Afterwards, uranium oxides and AHF are formed in a single step.

Two general processes were recommended which have a by-product other than AHF. One makes a depleted uranium oxide and a solid aluminum and fluoride compound which is used in the production of aluminum metal. The other technology uses depleted $\mathrm{UF}_{6}$ as a source of fluorine for making hydrofluorocarbons. Hydrofluorocarbons can be used instead of chlorofluorocarbons, which are believed to reduce ozone in the atmosphere.

Uranium Metal Suboptions. As discussed earlier, the more familiar processes for producing depleted uranium metal also produce large amounts of $\mathrm{MgF}_{2}$ waste. A different type of technology called plasma dissociation avoids the $\mathrm{MgF}_{2}$ waste stream. In this one-step process, a gas such as argon is heated to more than $5000^{\circ}$ centigrade or $9032^{\circ}$ Fahrenheit, using electrical energy. At these very high temperatures, depleted $\mathrm{UF}_{6}$ is broken down into uranium and fluorine atoms. After the gas cools, the fluorine atoms react with added hydrogen to produce AHF, and the uranium atoms combine with each other to form depleted uranium metal.

This process would avoid the uncertainties about the disposal of $\mathrm{MgF}_{2}$. It would also bring in more money from the sale of AHF, because all the fluorine in the depleted UF 6 is recovered. This process is in the early stage of development.

Several other recommendations contained improved ideas for removing uranium from $\mathrm{MgF}_{2}$. These recommendations also had suggestions for the recovery and possible use of by-products (for example, converting the $\mathrm{MgF}_{2}$ to $\mathrm{AHF}$ ). These advanced treatment technologies could reduce waste and be more economical. 


\subsection{Use Module}

Three use options are analyzed in less detail. These are (1) use as fuel for a light (regular) water power reactor, (2) use as fuel for an advanced power reactor, and (3) use in dense material applications. A number of people recommended these uses. The fuel options are analyzed in less detail because they would take a long time to use up significant amounts of depleted UF 6 . The long-term storage options discussed in the Engineering Analysis Report and the preferred alternative in the Draft PEIS would allow these, and other, uses to be reconsidered in the future. The environmental impacts of existing or new dense material applications are expected to be similar to those of the uranium metal radiation shielding option which is analyzed in depth.

Light Water Reactor Fuel Option. The main suboption for this use would involve re-enriching the depleted UF ${ }_{6}$ that is, increasing the percentage of U-235. The technologies that are used for enriching natural uranium could also be used to enrich depleted uranium. If all the U-235 in DOE's depleted UF, were recovered, it could provide fuel for the equivalent of about 100 power reactors operating for 10 years apiece. Re-enriching depleted uranium would save natural uranium resources and avoid the impacts of uranium mining and milling. However, only a small amount of the depleted uranium would actually be converted into enriched uranium. Most of the depleted uranium (over 90 percent) left after processing would still require management.

It is uncertain when re-enrichment would be economical. Continued storage preserves the possibility for the future, particularly for depleted uranium which has more than 0.3 percent U-235.

Another possible use of depleted uranium in light water reactors could involve converting the depleted $\mathrm{UF}_{6}$ to $\mathrm{UO}_{2}$. The depleted $\mathrm{UO}_{2}$ could then be mixed with plutonium oxide to produce mixed oxide fuel. However, this suboption would use up only a very small amount of the depleted $\mathrm{UF}_{6}$.

Advanced Reactor Fuel Option. One reason why DOE considered the depleted $\mathrm{UF}_{6}$ a valuable resource was its potential use in advanced reactors of the future. One such type of reactor, called a fast breeder reactor, actually produces additional fuel. Used in an advanced reactor, the depleted $\mathrm{UF}_{6}$ could provide hundreds of years of electrical power at the present U.S. production rate. However, this option would require a change in national policy, which is based on a once-through fuel cycle. In addition, since the advanced reactors are very fuel efficient, they would use up only a small amount of depleted uranium.

Dense Material Applications Option. Dense material applications include some ways in which depleted uranium metal is already being used, such as armor-piercing munitions, vehicle armor, ballasts in aircraft, and weights for stabilizing machinery. Other new uses were suggested in responses to the Request for Recommendations. These include energy storage flywheels (heavy metal wheels that store energy and make shafts rotate evenly), drill collars to keep oil well drill shafts centered, and explosives for the petroleum industry to open up the earth around natural gas and oil wells. Future dense material applications are uncertain at this time. The long-term storage options discussed in the Engineering Analysis Report and the preferred alternative in the Draft PEIS would allow these, and other, uses to be considered in the future. 


\subsection{Long-Term Storage Module}

Storage as depleted uranium metal and storage as depleted uranium tetrafluoride (UF 4 ) were considered but analyzed in less detail. Uranium metal bars would require much less space than oxides or $\mathrm{UF}_{6}$, but it costs much more to convert depleted $\mathrm{UF}_{6}$ to metal than to $\mathrm{U}_{3} \mathrm{O}_{8}$. In addition, there are safety issues with storage as metal. Unless it is protected, bulk uranium metal slowly corrodes. In air, the metal flakes can catch fire and release energy rapidly. The reaction between moisture and uranium metal creates hydrogen, which could explode if it collected in closed storage containers. For these reasons, storage as metal would require special packaging and more supervision.

Depleted uranium in the form of $\mathrm{UF}_{4}$ was considered for long-term storage or disposal but was analyzed in less detail. Conversion to $\mathrm{UF}_{4}$ is fairly simple and inexpensive, but another conversion step would probably be required before the material could be used. Depleted UF 4 is less chemically reactive than depleted $\mathrm{UF}_{6}$ but more reactive than the oxides and it would take up about the same amount of storage or disposal space as depleted $\mathrm{U}_{3} \mathrm{O}_{8}$. Other forms are more generally recommended for disposal.

\subsection{Disposal Module}

Disposal as depleted $\mathrm{UF}_{6}$, depleted uranium metal, and depleted $\mathrm{UF}_{4}$ were considered but analyzed in less detail. Regulations restrict the chemical forms that can be used for disposal. Reactive waste forms such as the fluorides and metal are specifically excluded by the Nevada Test Site and Hanford and by DOE Orders.

The Engineering Analysis Report analyzes bulk and cemented waste forms in detail. Another possible suboption is vitrification, in which depleted uranium oxide would be enclosed in glass. The basic technology is developed (for disposal of high-level radioactive waste), but other types of waste preparation are generally preferred for depleted uranium. Vitrified waste would require more space for disposal. In addition, a vitrification facility would be more complicated and costly to build and operate than a cementing facility.

\section{Roadmap for Integration of Engineering Data Input Reports into Long-Term Management Strategy Alternatives}

Figure 3 shows how complete management strategy alternatives can be put together from the options and suboptions analyzed in the Engineering Analysis Report. Depleted UF 6 stored in the cylinder yards at Paducah, Portsmouth, and Oak Ridge (the current management strategy) is shown at the left of the figure. Moving from left to right are the transportation, conversion, use, long-term storage, and disposal modules (work breakdown structure Level 2). 
The options and suboptions which are analyzed in depth are shown as blocks below the module names. The arrows on the chart indicate the flow of material for the various management strategies. Offsite transportation may be required between one option or suboption and another. This is shown by the small boxes marked "T." Activities such as construction of facilities, transportation of other materials and byproducts, and transportation and disposal of wastes are also included in the assessments of the management strategies. 


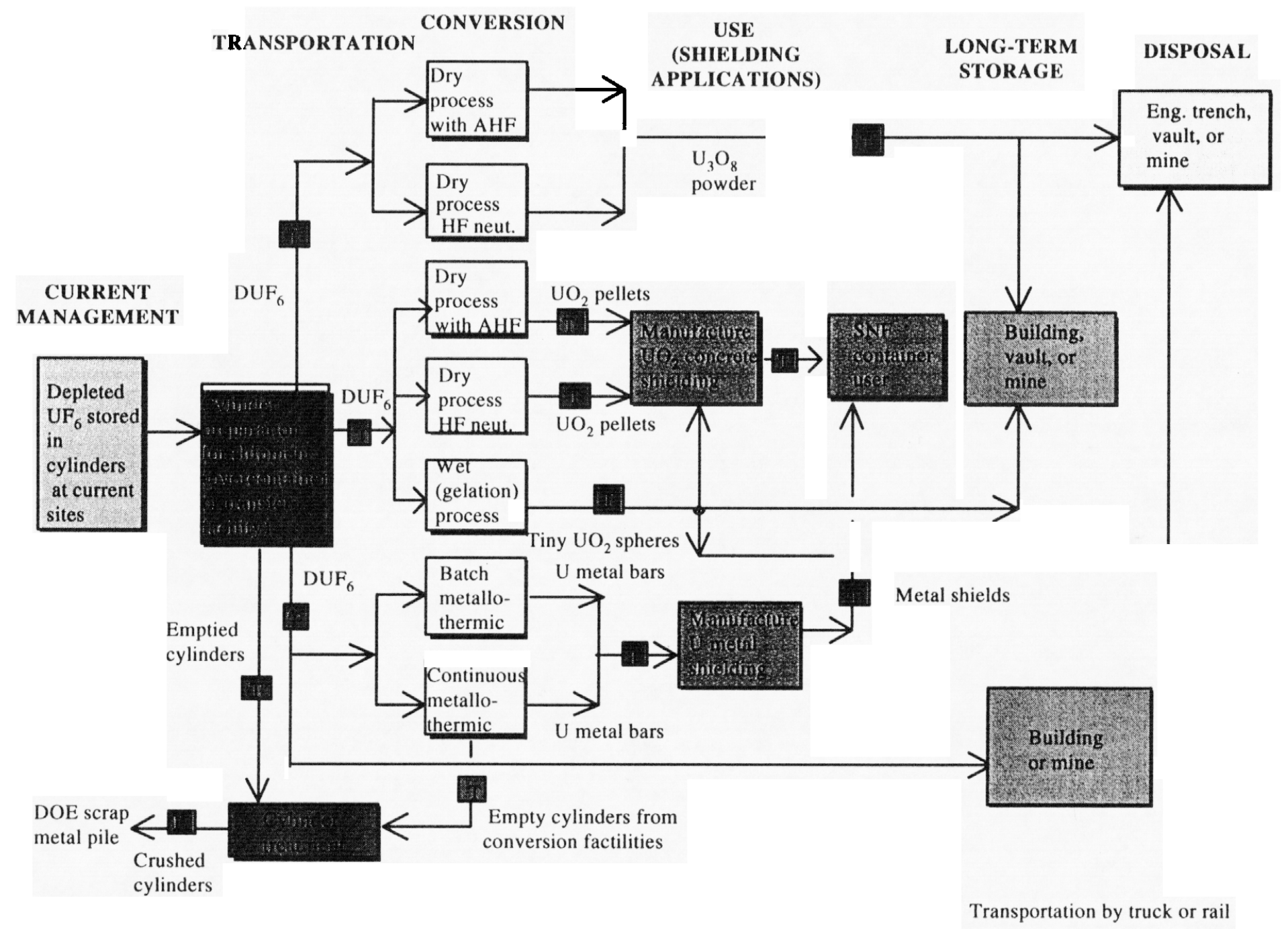

Figure 3. Flowchart for Developing Management Strategy Alternatives from Options and Suboptions 


\section{References}

Dubrin, J.W., et al. Engineering Analysis Report for the Long-Term Management of Depleted Uranium Hexafluoride. UCRL-AR-124080. Lawrence Livermore National Laboratory. May 1997.

Elayat, H., J.N. Zoller, and L. Szytel. Cost Analysis Report for the Long-Term Management of Depleted Uranium Hexafluoride. UCRL-AR-127650. Lawrence Livermore National Laboratory. May 1997.

U.S. Department of Energy. Draft Programmatic Environmental Impact Statement for Alternative Strategies for the Long-Term Management and Use of Depleted Uranium Hexafluoride. December 1997.

Zoller, J.N, et al. The Technology Assessment Report for the Long-Term Management of Depleted Uranium Hexafluoride. UCRL-AR-120372. Lawrence Livermore National Laboratory. June 30, 1995. 


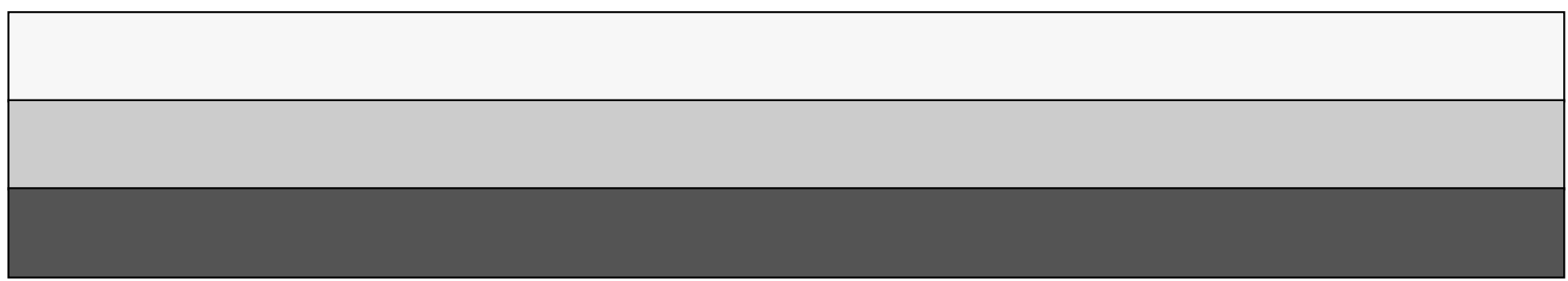

